\title{
Effects of a maternal high-fat diet on offspring behavioral and metabolic parameters in a rodent model
}

\author{
S. A. Johnson ${ }^{1,2,3}$, A. B. Javurek ${ }^{1,2}$, M. S. Painter ${ }^{1,2}$, C. R. Murphy ${ }^{1,2}$, C. M. Conard ${ }^{1,2}$, K. L. Gant ${ }^{1,2}$, E. C. Howald ${ }^{1,2}$, \\ M. R. Ellersieck ${ }^{3}$, C. E. Wiedmeyer ${ }^{4}$, V. J. Vieira-Potter ${ }^{5}$ and C. S. Rosenfeld ${ }^{1,2,6,7 *}$ \\ ${ }^{1}$ Bond Life Sciences Center, University of Missouri, Columbia, MO, USA \\ ${ }^{2}$ Biomedical Sciences, University of Missouri, Columbia, MO, USA \\ ${ }^{3}$ Agriculture Experimental Station-Statistics, University of Missouri, Columbia, MO, USA \\ ${ }^{4}$ Veterinary Medical Diagnostic Laboratory, Department of Veterinary Pathobiology, College of Veterinary Medicine, University of Missouri, Columbia, MO, USA \\ ${ }^{5}$ Nutrition and Exercise Physiology, University of Missouri, Columbia, MO, USA \\ ${ }^{6}$ Genetics Area Program, University of Missouri, Columbia, MO, USA \\ ${ }^{7}$ Thompson Center for Autism and Neurobehavioral Disorders, University of Missouri, Columbia, MO, USA
}

Maternal diet-induced obesity can cause detrimental developmental origins of health and disease in offspring. Perinatal exposure to a high-fat diet (HFD) can lead to later behavioral and metabolic disturbances, but it is not clear which behaviors and metabolic parameters are most vulnerable. To address this critical gap, biparental and monogamous oldfield mice (Peromyscus polionotus), which may better replicate most human societies, were used in the current study. About 2 weeks before breeding, adult females were placed on a control or HFD and maintained on the diets throughout gestation and lactation. $\mathrm{F}_{1}$ offspring were placed at weaning (30 days of age) on the control diet and spatial learning and memory, anxiety, exploratory, voluntary physical activity, and metabolic parameters were tested when they reached adulthood ( 90 days of age). Surprisingly, maternal HFD caused decreased latency in initial and reverse Barnes maze trials in male, but not female, offspring. Both male and female HFD-fed offspring showed increased anxiogenic behaviors, but decreased exploratory and voluntary physical activity. Moreover, HFD offspring demonstrated lower resting energy expenditure (EE) compared with controls. Accordingly, HFD offspring weighed more at adulthood than those from control fed dams, likely the result of reduced physical activity and EE. Current findings indicate a maternal HFD may increase obesity susceptibility in offspring due to prenatal programming resulting in reduced physical activity and EE later in life. Further work is needed to determine the underpinning neural and metabolic mechanisms by which a maternal HFD adversely affects neurobehavioral and metabolic pathways in offspring.

Received 28 April 2016; Revised 25 July 2016; Accepted 10 August 2016; First published online 9 September 2016

Key words: anxiety, cognition, developmental origins of health and disease, Peromyscus polionotus, spatial learning

\section{Introduction}

Obesity and its attendant medical costs afflict at least 35\% of the U.S. population, ${ }^{1}$ and about one-third of pregnant women are described as clinically obese. ${ }^{2}$ Maternal obesity can lead to severe health complications to the mother and immediate and possible long-term health consequences for her children and grandchildren. ${ }^{3,4}$ In addition, certain neurological diseases, for example depression, anxiety, attention deficit hyperactivity disorder and autism spectrum disorders (ASD), have been linked to maternal metabolic state. ${ }^{5-9}$ Maternal diet-induced obesity in both humans and laboratory animals has been linked to epigenetic alterations in key neural genes. ${ }^{10-16}$

Past rodent studies suggest that a maternal high-fat diet (HFD) can program later metabolic and neurobehavioral

*Address for correspondence: C. S. Rosenfeld, DVM, PhD, Associate Professor, Biomedical Sciences and Bond Life Sciences Center, University of Missouri, 440F Bond Life Sciences Center, 1201 E. Rollins Road, Columbia, MO 65211, USA

(Email rosenfeldc@missouri.edu) disruptions in adult offspring. One study suggests that rat offspring from dams fed a HFD demonstrate reduced body weight and growth, delayed physical maturation and suppression of physiological reflexes. ${ }^{17}$ Another study with rats indicates that a maternal HFD alters the expression of glucorticoid receptor $(G r)$ and downstream inflammatory genes in the hippocampus and amygdala and correspondingly decreases anxiety-like behaviors in adolescent offspring. ${ }^{18}$ Rat offspring derived from dams fed a HFD appear to be hypoinsulinaemic and hypoleptinaemic at birth, but by adulthood, are more obese, and show increased concentrations of insulin and leptin compared with controls. ${ }^{19}$ Perinatal exposure to a maternal HFD may also speed up the onset of puberty in female rats. ${ }^{20}$ In mice, a maternal HFD may increase body length and disturb glucose homeostasis across multiple generations. ${ }^{21}$

Additional studies have examined whether other nutrients may be used to mitigate the effects of a HFD, and whether sons and daughters demonstrate differing vulnerability to this imposed maternal diet. Mice offspring born to dams fed a HFD go on to show increased body weight gain, increased dietary fat preference 
in the case of male offspring, changes in central nervous system (CNS) gene expression, and global hypomethylation in the prefrontal cortex. ${ }^{22}$ However, concurrent maternal supplementation with a methyl-donor enriched diet combats these adverse effects. Male offspring born to rats fed a HFD during pregnancy and lactation and before conception show no anxiogenic behaviors, as determined by the elevated plus maze (EPM) (described below) but exhibit altered responses in the open field test, including increased zone entries and reduced thigmotaxis behavior (i.e. an organism's tendency to approach and seek contact with another object or fellow organism). ${ }^{23}$ These offspring also demonstrate reduced approach behavior and learning impairments, but sons born to mothers initially fed a HFD before conception, and then switched during gestation and/or lactation to a control diet, demonstrate improved performance, suggesting that there might be critical windows of time where maternal dietary intervention strategies can be employed to reverse the harmful effects of a HFD.

Many of the above studies employed laboratory mice and rats, which in some cases were inbred. Although such studies are helpful in elucidating how a maternal HFD can affect offspring outcomes, to recapitulate most human societies, it would be helpful to study such a maternal diet in an outbred monogamous animal model where both parents help raise the young. The oldfield mouse (Peromyscus polionotus) is monogamous and biparental, ${ }^{24,25}$ with the social bond between mated pairs essential in pup rearing (as we have shown for the related monogamous Peromyscus californicus). ${ }^{26}$ Their social structure is thus similar to most human societies. Consequently, we used oldfield mice to examine further how a maternal HFD may affect, in a sex-dependent manner, later offspring behavioral and metabolic parameters. Another important strength of this study is that, in the same group of animals, the effects of a maternal HFD on offspring behavioral and metabolic patterns were examined to determine if this diet simultaneously impacts the brain and metabolic organs. It should also be noted that the oldfield mouse model has been used widely in genetic, environmental, hormonal and toxicological studies. ${ }^{25,27-42}$ Moreover, this rodent model and other Peromyscus species have also been proposed to be complementary animal models to understand ASD in humans. ${ }^{34,43-46}$ In the current studies, $P_{0}$ females were exposed to a maternal HFD or control diet before conception and throughout lactation. The effects of a maternal HFD on later adult $F_{1}$ male and female offspring behaviors, spatial learning and memory, ability to extinguish a learned response, anxiety-like and exploratory behaviors, voluntary physical activity and metabolic parameters were then assessed.

\section{Materials and methods}

\section{Animal husbandry}

Outbred adult (60-90 days of age) founder oldfield female and male mice (Peromyscus polionotus subgriseus, PO stock) females and males, free of common rodent pathogens, were obtained from the Peromyscus Genetic Stock Center (PGSC) at the University of South Carolina (Columbia, SC, USA), and placed in quarantine for a minimum of 8 weeks to ensure that they did not carry any transmittable and zoonotic diseases. From the time ancestors were originally captured in the Ocala National Forest in 1952, P. polionotus subgriseus captive stocks have been bred by the PGSC to maintain their outbred status. All experiments were approved by University of Missouri Animal Care and Use Committee (Protocol \#7753) and performed in accordance with the recommendations in the Guide for the Care and Use of Laboratory Animals of the National Institutes of Health. About 2 weeks before breeding, 8-12 weeks of age females were randomly assigned to receive one of two diets: Control (7.2\% fat, TD.140790, Envigo, Madison, WI, USA) or HFD (22.2\% fat, TD.130957, Envigo). Nutrient composition of each diet is listed in Supplementary Table 1 . We weighed three dams on each of the diets at the time they were paired to establish that they were approximately the same weight at the time the diets were initiated. They were then weighed 1 and 2 weeks after being on their respective diets. After 2 weeks on the diets, females were then singly paired with males and continued on the diets until offspring were weaned at 30 days of age, the typical age for this species. Peromyscus species generally do not display copulatory plugs. However, we did not notice any preterm delivery, as has been reported in women consuming a HFD, ${ }^{47}$ or prolonged gestation for the two groups. After the females were paired to males and throughout the time they were nursing, they were minimally handled to avoid any stress that might cause them to abort, as this had been a concern while establishing the colony. Thus, we were not able to obtain any additional data on the dams.

Before being paired to females, all males were maintained on the control diet to avoid the HFD influencing their germ cell development and reproductive tract secretions, which could impact offspring metabolic and other outcomes. ${ }^{48-53}$ As this species is monogamous and biparental, the males were maintained with their breeding partner and offspring throughout the neonatal period.

The average litter size for $P$. polionotus is three to four pups. ${ }^{54}$ $F_{1}$ male and female offspring were weaned and placed on the control diet. Male and female offspring from the control and maternal HFD were tested at the same ages and order of tests. The total litters and number of $F_{1}$ male and female offspring used in the experiments below are listed in Supplementary Table 2. There were no differences in sex ratio for either diet group. As shown in Supplementary Table 2, for reasons that are not clear, in the same amount of time and with the same number of original females placed in each of the groups, there were more litter generated from dams on the HFD than the control diet, which is a standard gestational/lactational diet for rodents. Even so, the number of litters and offspring for both groups is on par and in some cases greater than total replicates tested in previous studies, which all show that a maternal HFD can affect offspring outcomes. ${ }^{17-23,55,56}$ 
The same group of animals was used in all tests detailed below.

\section{Barnes and reverse Barnes maze}

When $F_{1}$ offspring reached -90 days of age, their spatial learning and memory was tested in the Barnes maze. This test was performed as described previously for deer mice ( $P$. maniculatus bairdii) and California mice (P. californicus). ${ }^{57-60}$ The maze was comprised of a circular platform with 12 escape holes that were placed every $30^{\circ} .{ }^{61}$ To help guide the animal to the correct escape hole, four geometric shapes (triangle, square, circle and star) were placed $10 \mathrm{~cm}$ from the platform and evenly spaced (at $90^{\circ}$ intervals) along the maze wall. These served as intra-maze visual cues to help guide the animal to the correct escape hole. Before the behavioral testing, each animal was randomly assigned an escape hole that remained the same over the 5 days test period. To encourage the animal to enter the escape hole, a bright light $(1200 \mathrm{~lx} v$. testing room light $400 \mathrm{~lx})$ was placed over the maze to serve as a mildly aversive stimulus. The animals were habituated to the testing room conditions for $30 \mathrm{~min}$. They were then placed in the center of the maze and provided $300 \mathrm{~s}$ to locate the correct escape hole. If they did not find it on the 1st trial day, they were gently guided to it. Each trial was recorded with a Canon Vixia HF HD hand held camcorder (Canon, Melville, NY, USA). After the animals were rested for 1 week, they were retested with a reverse Barnes maze approach, where there was random reassignment of a different correct escape hole. The amount of time it took the animals to learn the new escape hole was then measured.

The initial and reverse Barnes maze behavioral trials were analyzed with the ANY-maze (Stoetling Co., Wood Dale, IL, USA) software analysis system for behavioral analysis. Indices that were measured with this program included time to enter the correct escape hole (latency), velocity, distance traveled, amount of time in the correct target zone and amount of time in the incorrect target zone. In addition, this program tracks the path the animals take to get from the center of the maze to the correct escape hole, which results in three main spatial strategies. A serial search strategy (Coded 1) was defined as continual search of consecutive holes in a clockwise or counterclockwise manner. A random search strategy (Coded 2) entailed the animal randomly searching non-escape holes while also crossing the center of the maze twice or more. The direct search strategy (Coded 3), which is the most efficient, was characterized with the animal entering the correct escape hole without crossing the center of the maze and entering no more than three incorrect holes.

\section{$E P M$}

The EPM measures exploratory and anxiety-like behaviors. This procedure was performed in the week between completion of the Barnes maze testing and initiation of the reverse Barnes maze testing, and the procedure was done as described previously. ${ }^{58-60,62}$ The EPM is arranged in a plus configuration and includes two opposite open arms $(30 \mathrm{~cm})$, a central platform region $(5 \times 5 \mathrm{~cm})$, and two opposite closed arms $(30 \mathrm{~cm})$. Each animal was placed in the center of the maze and permitted to explore it for $300 \mathrm{~s}$. Each trial was recorded with a Canon Vixia HF HD hand held camcorder (Canon). The video trials were then analyzed with the Observer Version 11 software (Noldus Technologies, Leesburg, VA, USA). Parameters measured include number of entries into the open and closed arms, duration of time spent in the open and closed arms and center, head dipping, which suggests exploratory, non-anxious behavior and rearing.

\section{Voluntary wheel running}

Voluntary wheel running was measured after the reverse Barnes maze procedure was performed. ${ }^{63}$ Metal exercise wheels (Kaytee, Chilton, WI, USA) with a diameter of 5.75 inches that were connected to a bicycle computer (Sigma Sport BC12.12, Sigma Sport USA LLC; St. Charles, IL, USA) were used to measure total distance traveled, average speed, maximum speed and total time spent running on the wheels for the 5-day trial period.

\section{Indirect calorimetric testing}

After completion of the above tests, adult (19-31-week old) animals were tested in the Promethion continuous measurement indirect calorimetry system (Sable Systems International, Las Vegas, NV, USA) for 3 days as described previously. ${ }^{63}$ The reason for this varying age range for this and subsequent experiments is that we sought to test the animals at a range of ages to determine whether the changes were stable over time. Moreover, this equipment is shared and heavily used, and, thus, it necessitates animals being tested in groups, which is another reason for the varying ages at the time of testing. Data were divided into $12 \mathrm{~h}$ light and $12 \mathrm{~h}$ dark cycles. Parameters that were measured include energy expenditure (EE), respiratory quotient (RQ) from oxygen consumption and $\mathrm{CO}_{2}$ production, and activity in the home cage as measured by beam breaks (X-vertical, $\mathrm{Y}$ - horizontal and Z-rearing), food and water intake.

\section{Echo magnetic resonance imaging (EchoMRI)}

After the indirect calorimetric testing was completed, the animals were tested in the EchoMRI-1100 (EchoMRI LLC, Houston, TX, USA) to measure body composition as described previously. ${ }^{63}$ Variables measured in a rapid and non-invasive manner included total and lean fat, free water and total water mass.

\section{Serum hormone analyses}

After completion of the echoMRI testing, the animals were fasted overnight. They were then humanely euthanized the next morning at $-8.30 \mathrm{am}$, and cardiac blood collected. The blood was centrifuged for $15 \mathrm{~min}$ at $7500 \mathrm{~g}$ in a Hettich 
Zentrisugen centrifuge (Hettich Lab Technology, Beverly, MA, USA). The serum fraction was then collected and stored at $-80^{\circ} \mathrm{C}$ until metabolite and hormone analyses were performed. Serum glucose was measured with a commercial clinical chemistry analyzer (Beckman-Coulter AU680; Beckman-Coulter, Brea, CA, USA) and automated, commercially available assay (Beckman-Coulter). Plasma insulin (Crystal Chem, Catalog \# 90080; Downers, Grove, IL, USA) and leptin (Crystal Chem, Catalog \# 90030) concentrations were analyzed according to the manufacturer's instructions for each of these ELISA kits, but without any serum dilution.

\section{Statistics}

SAS version 9.2 software analyses software (SAS Institute, Cary, NC, USA) was employed for these analyses. Unless otherwise stated, the reported data are based on mean \pm S.E.M. For all experiments, we first considered whether there were offspring and interactions of offspring $\times$ maternal sex or day effects. In those cases, were there were no main or interaction offspring effects, both sexes were considered together.

\section{Maternal periconception body weight}

As the maternal periconception body weight was collected at three time-points: at the time of being placed on the control or HFD, 1 and then 2 weeks later, these data were analyzed by a repeated measure ANOVA approach.

\section{Barnes and reverse Barnes maze}

Continuous random variables assessed in the Barnes maze, including distance traveled, velocity, error rate, were analyzed as a split plot in space and time. ${ }^{64}$ The linear statistical model contained the fixed effects of diet, sex, day and all possible interactions with diet, sex and day. To determine whether there were litter effects, source (dam $\times$ male) within diet was used as the denominator of $F$ for diet, source within day $X$ sex was used as the denominator for sex and interaction of diet $\times$ sex, source within day was used as the denominator of $\mathrm{F}$ for day and the remaining interaction used the residual mean square as the denominator of $\mathrm{F}$. Mean differences in body weight were determined by using Fisher's protected least significant difference (LSD).

Latency data were analyzed by using the PROC LIFETEST and Proportional Hazard Ratio (PROC PHREG) functions in the SAS version 9.2 software analyses. These analyses adjust for right-censoring (defined here as not locating the escape box within the allotted time of $300 \mathrm{~s}$ ) while still accommodating the study design of $300 \mathrm{~s} /$ trial. Data are reported as a hazard ratio that signifies the odds of a subject in a treatment group locating the correct escape hole compared with the other groups tested. A significant result indicates the odds are not $1: 1$. A result $>1$ indicates the test group was more likely to locate the correct escape hole than all other groups tested. A result $<1$ indicates that the treatment group is less likely to locate the correct escape hole compared with the other study groups. The litter was used as the denominator of $\mathrm{F}$ for the effects of maternal diet, offspring sex and test day, and potential interactions between maternal diet, offspring sex and test day. Latency data are reported as the mean, 95\% lower and upper confidence limit.

Search strategy data were analyzed by using a repeated measurement design with PROC GLIMMIX and SAS version 9.2 software analyses (SAS Institute). This analysis used a cumulative logit link and a multinomial distribution with all three search strategies included in this approach. As this initial analysis indicated a significant three-way interaction between maternal diet $\times \operatorname{sex} \times$ day, another cumulative logit analysis for each day was performed, where maternal diet, sex and maternal diet $\times$ sex interaction were modeled. To analyze the differences further, a third analysis on search strategy was performed on which the two less efficient strategies ( 1 and 2) were combined and compared against the more efficient search strategy (3), thereby resulting in a binomial distribution. The PROC GLIMMIX was again used where the model contrasted maternal diet, sex, maternal diet $\times$ sex effects for each day with a logit link. The differences between the least square means were based on average logits. Tabled data were converted to probabilities, which is the probability of a treatment group using one of the less efficient search strategies compared with the most efficient or direct search strategy.

\section{Elevated plus maze}

The amount of total time spent in the open and closed arms and center, as well as total number of arm entries, average velocity, total distance traveled, number of times engaged in head dipping and rearing were analyzed by a split plot design, as described above. The main variables included the effects of maternal diet, sex and maternal diet $\times$ sex.

\section{Indirect calorimetric testing}

The data were analyzed as a repeated measurement analysis in which the main plot contained the effects of the two maternal diets and two offspring sexes. The denominator of $F$ for the main plot was litter within maternal diet and offspring sex. The subplot contained the time series of both day and cycle. The day and cycle were factorial arranged in which the cycle contained two cycles (dark and light) and day contained the two days in which animals were measured in this unit. The subplot effect of day and cycle and day $\times$ cycle and the interactions of day and cycle with the main plot effect were tested using litter within maternal diet, offspring sex, day and cycle as the denominator of F. Fisher's protected LSD was tested if the overall of $\mathrm{F}$ was significant. In addition, as the animals were tested from 19 to 31 weeks of age, we divided the animals up into two age groups: 19 to 22 weeks and 23 to 31 weeks. The reason for these two groupings is that it allowed sufficient number of replicates in each of the maternal diets and sexes to be examined. We then considered for each of the categories measured with this equipment, the main effects of age and all 
possible interactions of age with maternal diet, sex, day and cycle.

\section{EchoMRI}

The data were analyzed as a complete randomized design (CRD) in which treatments were arranged as a two by two factorial (two maternal diets and two offspring sexes). As multiple pups came from the same litter, dam within maternal diet and offspring sex was used as the denominator of $\mathrm{F}$. If the overall $\mathrm{F}$ was significant, then differences were determined using Fisher's protected LSD.

\section{Voluntary wheel running}

The data were analyzed as a repeated measurement design in which the main plot contained maternal diet and offspring sex and maternal diet $\times$ offspring sex in a two by two factorial design. The subplot contained day and all possible interactions with the main plot effect. The denominator of $F$ for the main plot was dam within maternal diet and offspring sex. The denominator of $\mathrm{F}$ for the subplot effects was dam within maternal diet, offspring sex and day. Mean differences were determined using Fisher's protected LSD when the overall $\mathrm{F}$ test was significant.

\section{Serum hormone data}

For these data, the litter was considered the experimental unit. However, only on rare occasion, two animals originated from the same litter. The data were analyzed as a simple two by two factorial arrangement (two maternal diets and two sexes) considering the design as a CRD. If the overall $\mathrm{F}$ was significant, a Fisher's protected LSD was performed.

\section{Results}

\section{Maternal periconception body weight}

For the three time-points measured (day placed on diet, 1, and then 2 weeks afterwards), there was no effect of diet on maternal periconception body weight (Supplementary Table 4).

\section{Barnes and reverse Barnes maze}

There was a significant difference between offspring of the different maternal diets for the initial and reverse Barnes maze tests. Compared with controls, HFD offspring sniffed fewer incorrect holes, which equates to a decreased error rate, in the initial Barnes maze (Fig. 1a, $P=0.002$ ). However, the control group experienced a significant improvement between the initial and reverse maze $(P=0.0002)$, whereas the HFD group did not. For distance traveled, there was a significant interaction between the two Barnes maze trials and maternal diet, as well as the two trials and sex $(P=0.03$ and 0.05 , respectively). In the initial Barnes maze test, control animals traveled more distance than HFD individuals (Fig. $1 \mathrm{~b}, P=0.03$ ). Control individuals traveled more distance in the initial compared with the reverse Barnes maze $(P=0.02)$. Females traveled greater distance in the initial compared with the reverse Barnes maze (Supplementary Fig. 1, $P=0.01$ ). For velocity, the HFD group, but not the control group, significantly increased their locomotion speed in the reverse condition compared with the initial Barnes maze (Fig. 1c, $P=0.0002$ ).

For latency in both Barnes trials, there was a significant interaction between maternal diet and sex $(P=0.0001)$. Although no differences were evident in females between the two maternal diet groups, $F_{1}$ males in the HFD group demonstrated increased likelihood of solving the maze in the allotted time compared with control males (Fig. 2, $P=0.0001)$. Within the control group, female offspring were more likely to solve the maze than their male counterparts $(P=0.0001)$. These same sex differences were not evident in the HFD group. There were no differences in search strategy based on maternal diet, sex or Barnes $v$. reverse Barnes maze tests (Supplementary Fig. 2).

There were also differences based on sex $\times$ initial/reverse Barnes maze $\times$ day $(P=0.05)$. In the initial Barnes maze, both females and males learned to solve the maze over the 5-day trial period, as evidenced by the increased likelihood of locating the
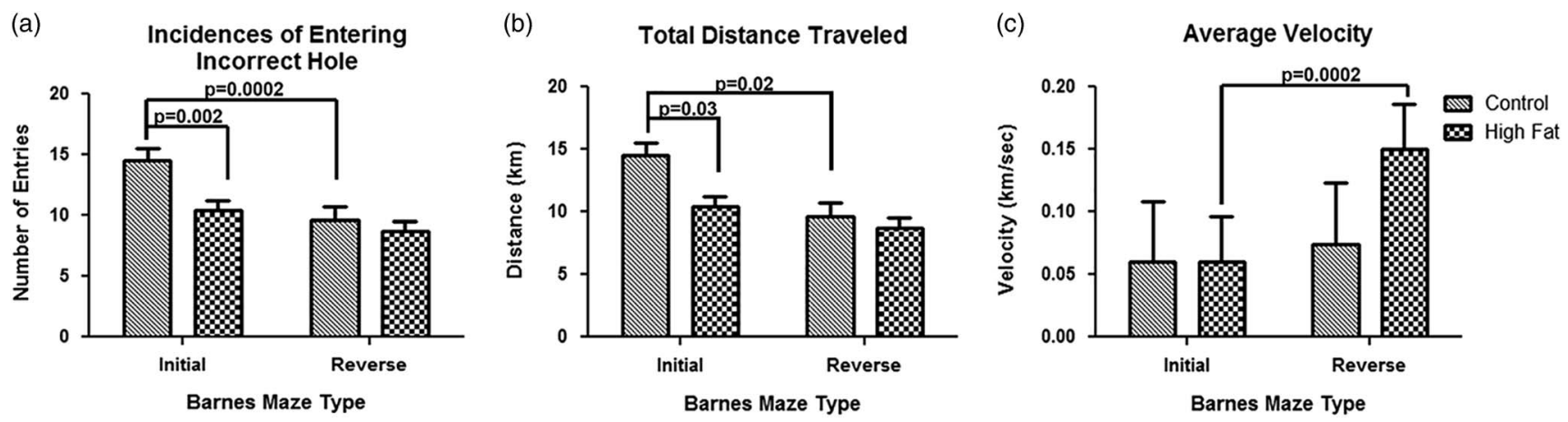

Fig. 1. Sniffing incorrect holes, distance traveled, velocity in the Barnes and reverse Barnes maze. (a) Sniffing incorrect holes. (b) Distance traveled. $(c)$ Velocity. Significant differences are designated with brackets between the values that differ and $P$-value above the brackets. 


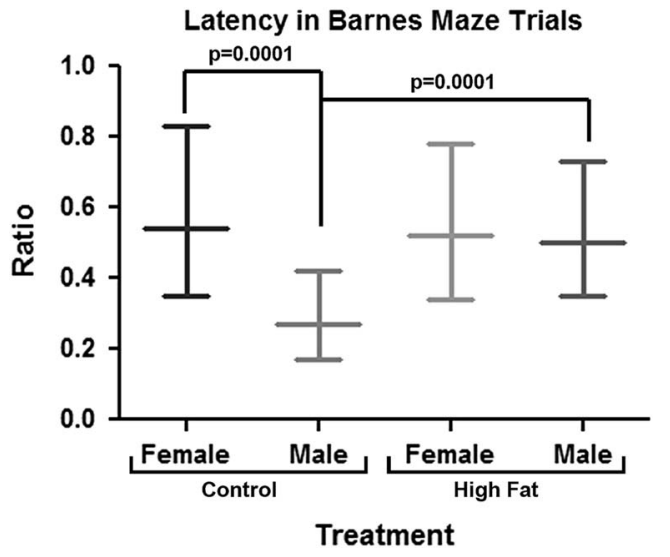

Fig. 2. Overall likelihood for females and males in each treatment group to locate the correct escape hole in the Barnes and reverse Barnes maze tests (latency). An increased ratio indicates shorter latency. The upper, middle and lower bars represent the ratio of locating the correct escape hole at the $95 \%$ upper confidence limit, mean, and $95 \%$ lower confidence limit, respectively, for each group to locate the escape hole relative to all other animals tested. Significant differences are designated with brackets between the values that differ and $P$-value above the brackets.

correct escape hole in the allotted time in later compared with the early trials (Supplementary Fig. 3a). Even by day 2, both sexes showed improved performance compared to the initial trial day $(P=0.002$ for females and $P=0.0001$ for males). This trajectory continued and became more pronounced in the later trial days (days 4 and 5, $P=0.0001$ ). However, the results for the reverse Barnes maze were not as clear (Supplementary Fig. 3b). In females, improved performance was only observed in day $2 v$. days 3 and $4(P=0.02)$. Male showed increased likelihood of solving the maze on days 4 and 5 compared with day $2(P=0.003$ and 0.01 , respectively). In addition, differences were observed between days 3 and 4 $(P=0.05)$.

\section{$E P M$}

For the duration of time spent immobile and mobile, there was a maternal $\operatorname{diet} \times \operatorname{sex}$ interaction $(P=0.04$ for both categories). $F_{1}$ adult daughters from dams fed the HFD spent more time immobile and less time mobile compared with $\mathrm{F}_{1}$ control daughters (Fig. 3a, $P=0.02$ ). HFD daughters also spent more time immobile and less time mobile that HFD sons $(P=0.02)$. No differences were detected across maternal diet groups for $\mathrm{F}_{1}$ males. The number of entries into the open or closed arms did not vary based on maternal diet or sex (Fig. 3b). Both groups entered the open arms more than the closed arms.

Head dipping, indicative of exploratory behavior, differed based on maternal diet $(P=0.05) . \mathrm{F}_{1}$ HFD offspring spent decreased amount of time engaging in this behavior compared with control offspring (Fig. 3c). The mean time spent rearing, which is considered a stereotypical behavior, varied according to maternal diet $\times \operatorname{sex}(P=0.05)$. $\mathrm{F}_{1}$ HFD males spent greater mean time rearing than control males and $\mathrm{F}_{1}$ HFD females (Fig. $3 \mathrm{~d}, P=0.03$ and 0.01 , respectively).

\section{Voluntary wheel running}

There were no differences in distance traveled or average speed based on maternal diet or offspring sex (Supplementary Fig. 4).

\section{Indirect calorimetry}

Total EE, indicative of total energy expended in kcal, did not differ. Resting EE differed based on a maternal $\operatorname{diet} \times$ circadian cycle as indicated by a significant statistical interaction $(P=0.008)$. During the dark (i.e. rodent active cycle), control individuals demonstrated greater resting $\mathrm{EE}$ compared with maternal HFD offspring (Fig. 4, $P=0.03$ ). In controls, resting $\mathrm{EE}$ was greater during the dark cycle compared with the light cycle $(P=0.0001)$, but such circadian differences were not evident in the HFD group which may indicate that the maternal HFD reduced resting EE during the rodent's active cycle.

For resting $\mathrm{EE}$, there was also an age $\times$ sex interaction $(P=0.03)$. At $23-31$ weeks of age, females trended to show a lower EE than males ( $P=0.06$, Supplementary Fig. 5$)$.

Average food consumption showed significant differences based on maternal $\operatorname{diet} \times \operatorname{sex} \times$ cycle interaction effects $(P=0.01)$. During the light cycle, food consumption (both of these offspring groups were maintained on the same control diet) was greater for control females than HFD females (Fig. $4 b, P=0.002$ ). No treatment differences though were observed in male offspring (Fig. 4c).

For average food consumption, there were also significant differences based on maternal diet $\times$ age $\times$ cycle interaction effects $(P=0.004)$. At $19-22$ weeks of age, control animals consumed more food during the dark compared with the light cycle (Supplementary Fig. 6, $P=0.001$ ). In comparing across age groups, control animals ate more during the light cycle from 23 to 31 weeks compared with 19-22 weeks $(P=0.0006)$. Conversely, control animals ate more during the dark cycle at 19-22 weeks than at 23-31 weeks $(P=0.05)$. At 19-22 weeks of age, control animals ate more during the dark cycle than HFD animals of this age range $(P=0.02)$. At 23-31 weeks of age, control animals ate more during the light compared with the dark cycle $(P=0.001)$. Further, at this same age, control animals ate more during the light cycle than HFD animals $(P=0.001)$.

Several indices measured in the indirect calorimetry suggested that the maternal HFD suppressed voluntary physical activity in resulting adult offspring. The number of times individuals broke the beams on the $\mathrm{X}, \mathrm{Y}$, or $\mathrm{Z}$ axis (XYZ Breaks) varied based on $\operatorname{diet} \times$ cycle interaction effects $(P=0.02)$. During the dark cycle, control individuals broke the beams more times than those in the HFD group (Fig. $5 \mathrm{a}, P=0.003$ ). Both control and HFD individuals broke the beams more times during the dark than the light cycle $(P=0.0001)$. Males in both combined groups broke the XYZ beams more times during the 
(a)
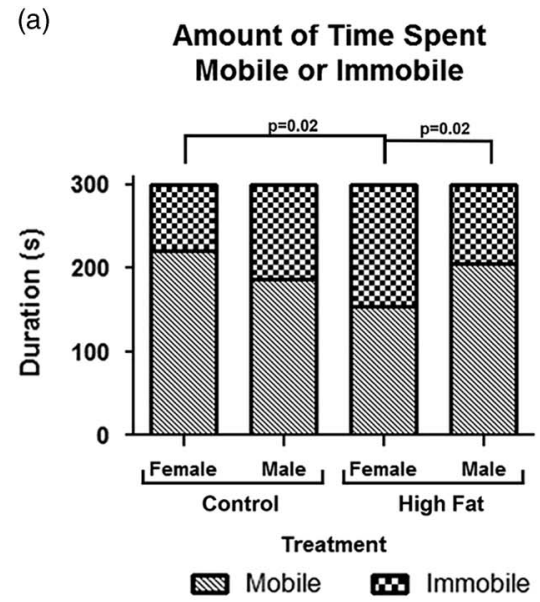

(c)

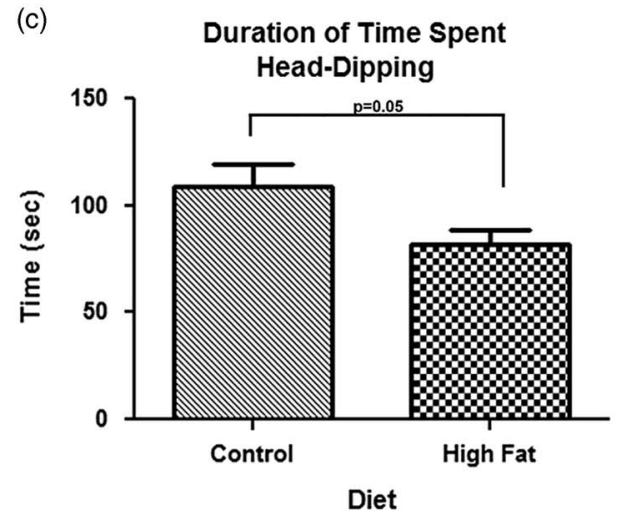

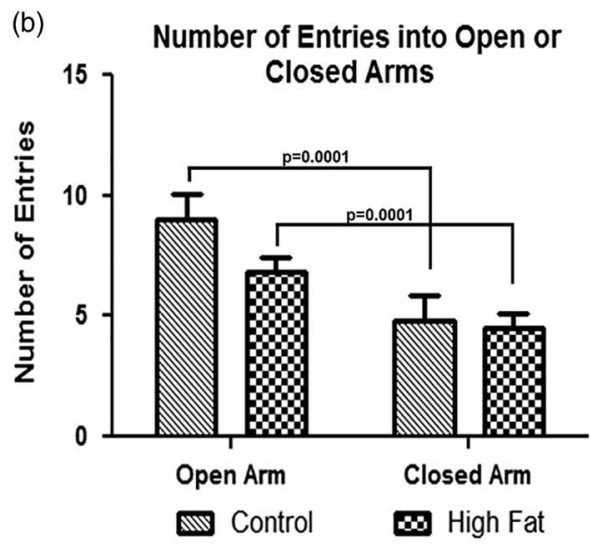

(d)

Mean Time Spent Rearing

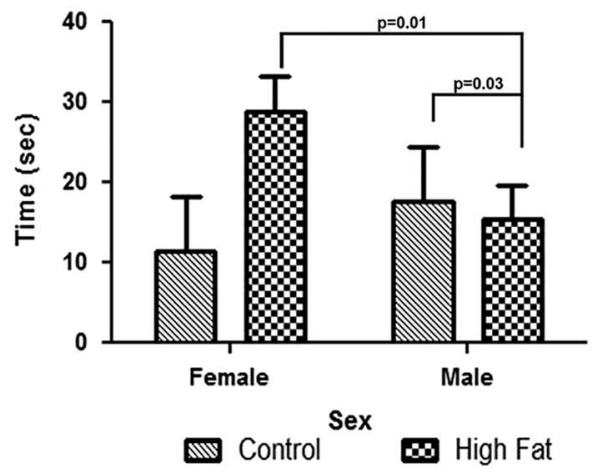

Fig. 3. Elevated Plus Maze results. (a) Time spent immobile and mobile. (b) Entries into open and closed arms. (c) Duration of time spent head dipping. (d) Mean time spent rearing. Significant differences are designated with brackets between the values that differ and $P$-value above the brackets.
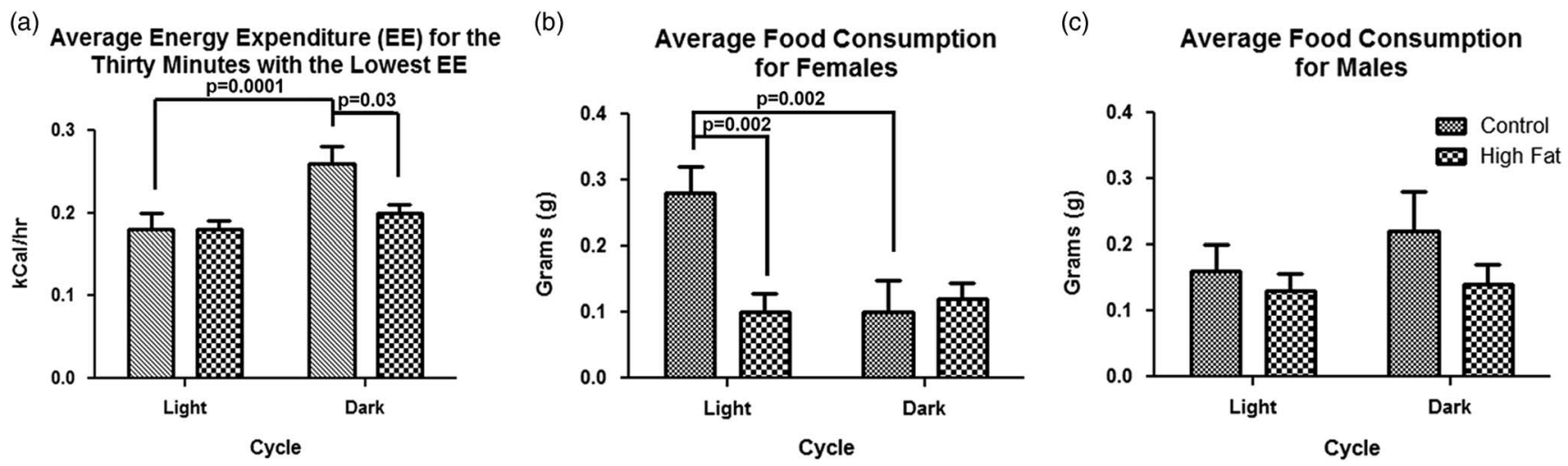

Fig. 4. Average energy expenditure (EE) and food consumption. (a) Average EE for 30 min with the lowest EE (resting EE). (b) Average food consumption for females. $(c)$ Average food consumption for males. Significant differences are designated with brackets between the values that differ and $P$-value above the bracket.

dark cycle than females in both groups (Supplementary Fig. 7, $P=0.007)$. Total distance walked differed based on maternal diet $\times$ cycle interaction effects $(P=0.01)$. During the dark cycle, control individuals walked more than those in the HFD group (Fig. $5 \mathrm{~b}, P=0.003$ ). The percentage of time spent walking and remaining still also varied according to maternal 
(a)

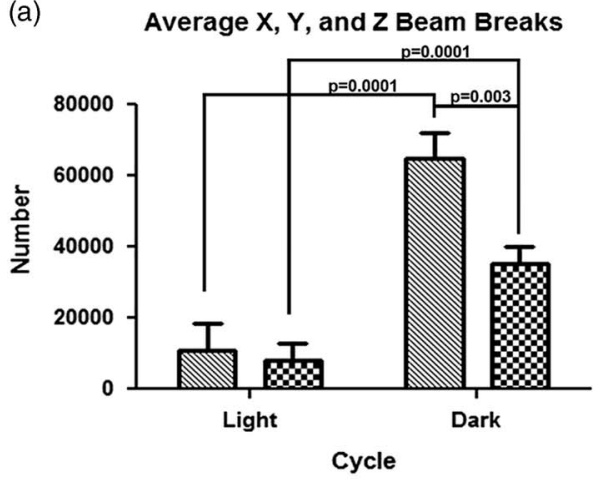

(c)

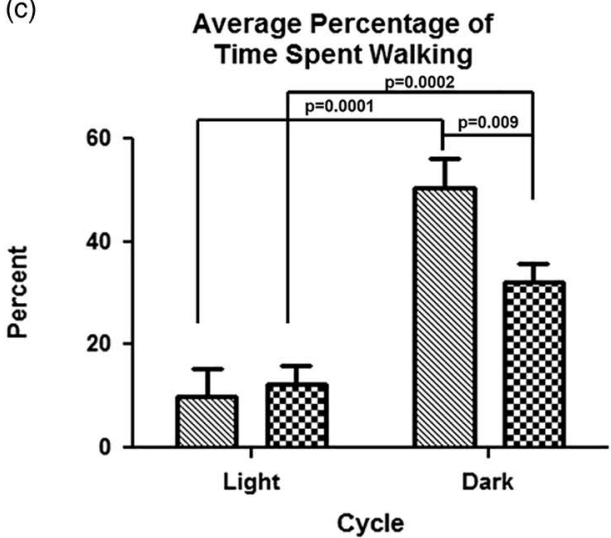

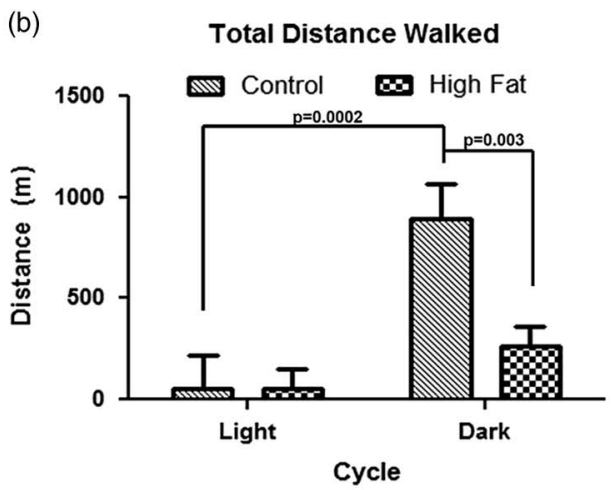

(d)

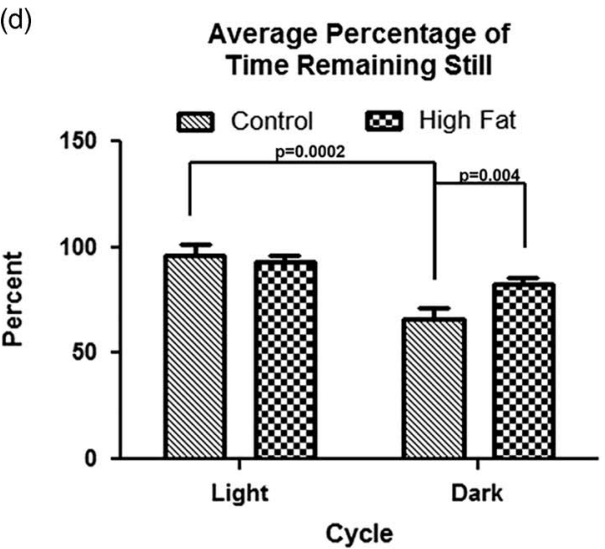

Fig. 5. Voluntary physical activity home-cage setting assessments. (a) X, Y, and Z beam break measurements. (b) Total distance traveled. (c) Percentage of time spent walking. (d) Percentage of time remaining still. Significant differences are designated with brackets between the values that differ and $P$-value above the bracket.

$\operatorname{diet} \times$ cycle $(P=0.02$ and 0.01 , respectively). Control animals walked a greater percentage during the dark cycle than HFD individuals (Fig. 5c, $P=0.009$ ). Conversely, HFD individuals spent more time remaining still during the dark cycle than control counterparts (Fig. 5d, $P=0.004$ ).

For these above parameters, only total distance walked was influenced by maternal diet $\times$ age $\times$ sex. At $19-22$ weeks of age, control females tended to walk more than HFD females (Supplementary Fig. 8, $P=0.06$ ). At 23-31 weeks of age, control females walked less than control males $(P=0.01)$. At this same age range, control males walked more than HFD males $(P=0.02)$.

The percentage of time spent sleeping was significantly altered by maternal diet $\times$ cycle effects $(P=0.004)$. HFD animals spent a greater percentage of time sleeping during the dark cycle than controls (Supplementary Fig. 9a, $P=0.0004$ ). Both controls and HFD animals spent a greater percentage of time sleeping during light $v$. dark cycle $(P=0.0001)$. The total hours spent sleeping was significantly affected by maternal diet $\times$ cycle effects $(P=0.004)$. During the dark cycle, HFD offspring slept more than controls (Supplementary Fig. 9b, $P=0.0004$ ). Both control and HFD offspring slept more during the light compared with the dark cycle $(P=0.0001)$.

\section{EchoMRI}

Adult body weight differed based on maternal diet $(P=0.01)$. Sons and daughters born to dams on the HFD weighed more as adults that those born to dams on the control diet (Fig. 6a). Adult lean tissue was also greater in offspring exposed to a maternal HFD $(P=0.002)$. Control females and males had less lean tissue mass than HFD counterparts (Fig. 6b, $P=0.008$ and 0.01 , respectively).

\section{Serum metabolites and hormones}

No differences were detected based on maternal diet or sex for serum glucose, insulin or leptin concentrations (Table 1).

\section{Discussion}

The primary goal of this study was to examine how maternal periconception through lactation exposure to a HFD in oldfield mice affected behavioral and metabolic parameters in her adult $F_{1}$ male and female offspring. Counter to expectations, male offspring exposed to the maternal HFD showed improved spatial learning and memory ability compared with control males. This was evident by the fact that the latter group was more likely to solve the initial and reverse Barnes maze in the allotted 
(a)

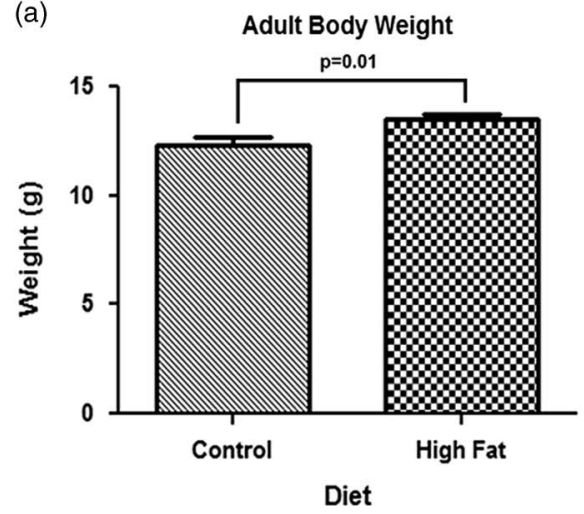

(b) Amount of Lean Tissue and Fat Mass

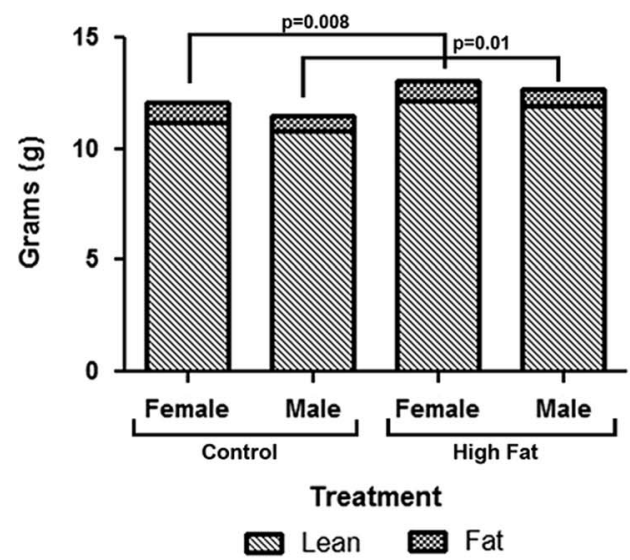

Fig. 6. Echo magnetic resonance imaging results. (a) Adult body weight. (b) Lean and fat tissue mass. Significant differences are designated with brackets between the values that differ and $P$-value above the bracket.

Table 1. Measurements of serum glucose and metabolic hormone concentrations in offspring

\begin{tabular}{lcccc}
\hline & Control female & Control male & HFD female & HFD male \\
\hline Glucose $(\mathrm{mg} / \mathrm{dl})$ & $157.3 \pm 87.3$ & $114.0 \pm 90.0$ & $150.0 \pm 139.1$ & $139.6 \pm 103.8$ \\
Insulin $(\mathrm{ng} / \mathrm{ml})$ & $0.20 \pm 0.17$ & $0.15 \pm 0.05$ & $0.15 \pm 0.04$ & $0.27 \pm 0.32$ \\
Leptin $(\mathrm{ng} / \mathrm{ml})$ & $0.39 \pm 0.1$ & $0.36 \pm 0.15$ & $0.37 \pm 0.14$ & $0.38 \pm 0.13$ \\
\hline
\end{tabular}

HFD, high-fat diet.

time (shorter latency) and thus traveled less distance in the maze. A prior study with Wistar rats found that maternal obesity due to a HFD resulted in learning deficits in $\mathrm{F}_{1}$ offspring. ${ }^{56}$ Analogous results were reported in Sprague-Dawley rat offspring born to dams fed a HFD in that they took longer and swam more in the Morris Water Maze, which also measures spatial learning and memory. ${ }^{65}$ That study also showed that the HFD offspring had gene expression changes in the hippocampus with nerve growth factor $(N g f)$ and $N$-methyl- $d$-aspartate receptor (NMDA) receptor subunit NR2b (Grin2b) decreased but synaptotagmin $(S y t 1)$ increased. In mice offspring, a maternal HFD impaired performance in the Barnes maze, increased lipid peroxidation in the hippocampus, decreased dendritic arborization in hippocampal neurons and suppressed brain-derived neurotrophic factor $(B d n f)$ expression in the hippocampus. ${ }^{66}$ It is not clear why the current findings differ from those earlier studies. It may relate though to the varying animal models tested. In oldfield mice, which tend to be smaller than most laboratory mice and rats, development of this cognitive domain may benefit from a maternal HFD; whereas, a similar maternal diet in mice and rats may result in adverse effects on later spatial learning and memory. The age at which the animals are tested may also affect the results. Although HFD males may show initial improvements in spatial learning and memory, they could also show premature cognitive decline relative to controls.
Another possibility for the conflicting data may be due to variation in the diet composition used in the past studies relative to the current studies. In prior experiments, the fat $\mathrm{kcal}$ $\%$ ranged from 34.9 to $57.8,{ }^{56,65,66}$ whereas in the current work it was $43.8 \%$ (Supplementary Table 1 ). There were also variations across studies in the $\mathrm{kcal} / \mathrm{g}$, protein and carbohydrate content in the diets tested. Similar to our experimental design, these above studies exposed the females to the HFD before mating (periconception period) and throughout most if not all of lactation. ${ }^{56,65,66}$ However, in these studies, the females were exposed to the diet from 4 to 6 weeks before mating, which could lead to varying results. It is increasingly becoming clear that different exposure windows, periconception, gestation and/or lactation, can induce contrasting offspring $\mathrm{DOHaD}$ outcomes. $^{67-70}$ Thus, future work may need to test this and other behaviors at multiple ages, test diets containing a range of fat content, and examine different exposure windows during these three critical periods.

The two Barnes maze trials also reveal that in the control group, females outperform males, as indicated by increased likelihood of solving the maze. This finding is surprising in light of our prior studies with related Peromyscus cousins. In polygynous deer mice (P. maniculatus bairdii), males showed enhanced spatial learning and memory compared with females. ${ }^{57-59}$ In this species, this behavior is considered a sexually selected trait, as sexually mature adult males relay on spatial abilities to locate potential 
reproductive partners that are widely dispersed throughout the environment. In contrast, this behavior does not confer any advantage and may actually put female deer mice at risk for increased predation. Conversely, monogamous California mice (P. californicus) do not demonstrate any sex differences in spatial navigation. ${ }^{57,60}$ In oldfield mice, females forage for food for themselves and their offspring, and increased spatial ability might allow them to recall the best food sites. We previously found that female Sprague-Dawley rats demonstrate enhanced spatial learning and memory compared with males. ${ }^{71}$ The combined results suggest that sex-differences in spatial learning and memory may depend on mating strategies and which sex is the primary nutritional provider.

Anxiety-like and exploratory behaviors were assessed with the EPM. Decreased mobility by $\mathrm{F}_{1}$ HFD females in the EPM suggests that they are more anxious, less exploratory than their control counterparts. Decreased exploratory behavior was also evident as both $\mathrm{F}_{1}$ HFD females and males spent less time engaging in head dipping behavior. In contrast, $\mathrm{F}_{1}$ HFD males spent more time rearing, a stereotypical behavior, than $F_{1}$ control males. Prior rodent studies have shown disparate results as to whether a maternal HFD results in increased anxiety-like behaviors in their offspring. ${ }^{18,23,72-74}$ Sex, age at the time of behavioral testing, and different rodent models might account for the conflicting findings. In humans, maternal obesity has been linked with child obesity, increased inflammation and anxiety disorders. ${ }^{75-79}$ Besides neural inflammation, a maternal HFD might disrupt anxiety responses via glucocorticoid receptor, gamma-aminobutyric acid, serotonergic and neurotrophin signaling pathways. ${ }^{18,72-74}$

During the time period assessed, no differences in wheel running were observed between the maternal HFD and control offspring. It has been previously reported that Peromyscus spp., including $P$. polionotus, run more on running wheels than Microtus species. ${ }^{80}$ It is possible that if the running wheel were left in the cages for several months, differences would emerge between the two groups. For instance, HFD offspring might become more habituated and less likely to use the wheels than controls. This possibility is currently being explored. There may also be species and sex-differences in vulnerability to maternal diet changes and usage of voluntary wheels in her offspring. For instance, ad libitum feeding of a maternal HFD to Sprague-Dawley rats resulted in decreased voluntary wheel running in her sons, but increased time spent on them by her daughters. ${ }^{81}$

Although no maternal diet-induced changes in offspring physical activity were observed with the voluntary wheels, dramatic differences were detected with indirect calorimetry testing, which may be a better assessment of general home-cage activity. Several indices, including $\mathrm{X}, \mathrm{Y}$ and $\mathrm{Z}$ beam breaks, percentage and total duration of time spent walking, distance traveled and percentage and total duration of time spent sleeping, strongly indicate that offspring born to dams on the HFD are less active than control counterparts. During the rodent active cycle, control offspring were more likely to move around the cage than HFD offspring. In contrast, sons and daughters exposed to the maternal HFD were more likely to sleep during this time, which is generally considered the height of rodent activity. Correspondingly, controls demonstrated greater EE during the dark cycle than HFD progeny.

Our prior studies indicate that maternal exposure of related California mice ( $P$. californicus) to the endocrine disrupting chemical, bisphenol A (BPA), resulted in analogous findings in terms of decreased voluntary physical activity. ${ }^{63}$ BPA has been proposed to be an obesogen, especially when exposure occurs during the perinatal period. ${ }^{82-84}$ Thus, it is not surprising that similar findings are observed in progeny of dams exposed to a HFD or BPA. In light of the significant prevalence of obesity during pregnancy, combined with potential endocrine disruptive agents in our environment, future studies should determine if maternal co-exposure to a HFD and BPA exacerbates physical inactivity in resulting offspring.

In sheep, maternal undernutrition is associated with decreased voluntary physical activity by adult offspring. ${ }^{85}$ Similar findings were reported in Wistar rat offspring derived from undernourished mothers. ${ }^{86}$ Moreover, provisioning these offspring with a hypercaloric diet at weaning accentuated the physical inactivity, Fetal growth restriction of offspring derived from viable yellow $\left(A^{v y} / a\right)$ mice dams results in later physical inactivity and obesity. ${ }^{87}$ An epidemiological study with parents and offspring in South India revealed that offspring physical activity significantly correlated with physical activity level of the mother but not the father. ${ }^{88}$

Mechanistically, reduced spontaneous cage activity in the home-cage setting for HFD sons and daughters may be due to disturbances in brain regions governing this behavior, such as the hypothalamus, hippocampus, amygdala, prefrontal cortical region, nucleus accumbens, caudate-putamen, mid-brain, locus coeruleus and pons. ${ }^{89-96}$ A maternal HFD may also lead to changes in neural transcripts modulating voluntary physical activity, including DeltaFosb, ${ }^{97}$ dopamine receptor and transporter (Drd1-5 and SlcA3), $\left.{ }^{98-104} B d n f\right)^{95,105,106}$ orexin and orexin receptor $(O x a$ and $O x r) .^{96,107-111}$ Future studies will thus be designed to test whether a maternal HFD alters these neural transcripts and brain regions. If so, therapies may be designed to correct these gene expression imbalances.

We found that HFD progeny weighed more than controls, although we did not see any changes in fat content. Earlier and later time-points are currently being examined to elucidate the etiology and potential significance of this phenotypic change. Other animal model and human epidemiological studies suggest that offspring born to obese mothers and those consuming a HFD show a greater preponderance to become obese as well. ${ }^{112-116}$ Given the body weight differences, we predicted that there would be alterations in serum metabolites and hormones. However, serum glucose, insulin and leptin concentrations in fasted animals did not differ based on maternal diet. A prior study showed that HFD rat offspring demonstrate decreased circulating concentrations of insulin and leptin at birth but by adulthood, these hormones are elevated relative to control, non-obese offspring. ${ }^{19}$ 
The combined studies suggest that there could also be species and temporal differences as to how a maternal HFD affects these factors. Other metabolic hormones, including orexin, adiponectin, thyroxin and corticosterone, may also be affected by maternal nutritional state and will thus be considered in future studies.

In this study, males were not exposed to the HFD until the time they were paired to females. Thus, it is unlikely that this diet could affect their germ cells or male reproductive tract secretions. Prior studies have indicated that a paternal HFD can alter both of these factors and thereby affect offspring outcomes. ${ }^{48-53}$ However, we cannot rule out the possibility that exposure to the HFD may compromise biparental care provided to the pups, as we observed in male and female California mice developmentally exposed to BPA or ethinyl estradiol. ${ }^{117}$ To our knowledge, no studies to date have examined whether a HFD can alter maternal or paternal care. Thus, this possibility should be explored in future studies. Another likelihood that should be considered is that biparental care, which is unique to oldfield mice, other Peromyscus species and certain vole species, may mitigate some of the deleterious effects of a maternal HFD that are observed in laboratory mice, rats and other polygynous species, where the male reproductive partner generally does not show any significant parental care and may even cannibalize the pups if left in the cage with them. Our model may thus better approximate most human societies that are generally monogamous and where both parents share parental responsibilities.

In previous studies, we found that a maternal HFD with $60 \%$ calories as fat resulted in sex ratio distortions to males in parities two through four but not the first parity. ${ }^{55}$ No such sex ratio bias was observed in the current studies that used a maternal HFD with $43.8 \%$.

In conclusion, the current work with oldfield mice demonstrates that perinatal exposure to a HFD disrupts select behavioral domains and metabolic parameters. Puzzlingly, maternal HFD male offspring were more likely to solve the Barnes and reverse Barnes maze compared to control males. Female offspring exposed to a HFD exhibit increased anxiogenic behaviors. Voluntary physical activity in a home-cage setting was suppressed in HFD female and male offspring relative to controls. Consistently, HFD progeny also weighed more than controls. Further work is thus needed to determine the underpinning mechanisms of how a maternal HFD disturbs brain and metabolic programming in a potentially sex-specific manner.

\section{Acknowledgments}

The authors thank Dr Michael R. Felder at the University of South Carolina for providing the founder oldfield mice. The authors thank Dr Jonathan P. Thyfault for providing expertise in designing the indirect calorimetry experiments and Rebecca J. Welly for analyzing the indirect calorimetry data.

\section{Financial Support}

The studies were supported by NIH Grant 5R21ES023150 (to C.S.R.).

\section{Conflicts of Interest}

None.

\section{Ethical Standards}

The authors confirm that all procedures were performed in accordance with the recommendations detailed in the Guide for the Care and Use of Laboratory Animals by the National Institutes of Health and have been approved by the University of Missouri Animal Care and Use Committee.

\section{Supplementary material}

To view supplementary material for this article, please visit http://dx.doi.org/10.1017/S2040174416000490

\section{References}

1. Ogden CL, Carroll MD, Kit BK, Flegal KM. Prevalence of childhood and adult obesity in the United States, 2011-2012. JAMA. 2014; 311.

2. King JC. Maternal obesity, metabolism, and pregnancy outcomes. Annu Rev Nutr. 2006; 26, 271-291.

3. Kliegman RM, Gross T. Perinatal problems of the obese mother and her infant. Obstet Gynecol. 1985; 66, 299-306.

4. Roseboom TJ, Watson ED. The next generation of disease risk: are the effects of prenatal nutrition transmitted across generations? Evidence from animal and human studies. Placenta. 2012; 33(Suppl. 2), e40-e44.

5. Krakowiak P, Walker CK, Bremer AA, et al. Maternal metabolic conditions and risk for autism and other neurodevelopmental disorders. Pediatrics. 2012; 129, e1121-e1128.

6. Rizzo TA, Silverman BL, Metzger BE, Cho NH. Behavioral adjustment in children of diabetic mothers. Acta Paediatr. 1997; 86, 969-974.

7. Sullivan EL, Nousen EK, Chamlou KA. Maternal high fat diet consumption during the perinatal period programs offspring behavior. Physiol Behav. 2012; 123, 236-242.

8. Jones KL, Will MJ, Hecht PM, Parker CL, Beversdorf DQ. Maternal diet rich in omega- 6 polyunsaturated fatty acids during gestation and lactation produces autistic-like sociability deficits in adult offspring. Behav Brain Res. 2013; 238, 193-199.

9. Lyall K, Munger KL, O’Reilly EJ, Santangelo SL, Ascherio A. Maternal dietary fat intake in association with autism spectrum disorders. Am J Epidemiol. 2013; 178, 209-220.

10. Aagaard-Tillery KM, Grove K, Bishop J, et al. Developmental origins of disease and determinants of chromatin structure: maternal diet modifies the primate fetal epigenome. $J \mathrm{Mol}$ Endocrinol. 2008; 41, 91-102.

11. Attig L, Vige A, Gabory A, et al. Dietary alleviation of maternal obesity and diabetes: increased resistance to diet-induced obesity transcriptional and epigenetic signatures. PLoS One. 2013; 8, e66816. 
12. Borengasser SJ, Zhong Y, Kang P, et al. Maternal obesity enhances white adipose tissue differentiation and alters genomescale DNA methylation in male rat offspring. Endocrinology. 2013; 154, 4113-4125.

13. Li CC, Maloney CA, Cropley JE, Suter CM. Epigenetic programming by maternal nutrition: shaping future generations. Epigenomics. 2010; 2, 539-549.

14. Li CC, Young PE, Maloney CA, et al. Maternal obesity and diabetes induces latent metabolic defects and widespread epigenetic changes in isogenic mice. Epigenetics. 2013; 8, 602-611.

15. Lillycrop KA. Effect of maternal diet on the epigenome: implications for human metabolic disease. Proc Nutr Soc. 2011; 70, 64-72.

16. Yang QY, Liang JF, Rogers CJ, et al. Maternal obesity induces epigenetic modifications to facilitate Zfp423 expression and enhance adipogenic differentiation in fetal mice. Diabetes. 2013; 62, 3727-3735.

17. Mendes-da-Silva C, Giriko CA, Mennitti LV, et al. Maternal high-fat diet during pregnancy or lactation changes the somatic and neurological development of the offspring. Arq Neuropsiquiatr. 2014; 72, 136-144.

18. Sasaki A, de Vega W, Sivanathan S, St-Cyr S, McGowan PO. Maternal high-fat diet alters anxiety behavior and glucocorticoid signaling in adolescent offspring. Neuroscience. 2014; 272, 92-101.

19. Howie GJ, Sloboda DM, Kamal T, Vickers MH. Maternal nutritional history predicts obesity in adult offspring independent of postnatal diet. J Physiol. 2009; 587(Pt 4), 905-915.

20. Sloboda DM, Howie GJ, Pleasants A, Gluckman PD, Vickers $\mathrm{MH}$. Pre- and postnatal nutritional histories influence reproductive maturation and ovarian function in the rat. PLoS One. 2009; 4, e6744.

21. Dunn GA, Bale TL. Maternal high-fat diet promotes body length increases and insulin insensitivity in second-generation mice. Endocrinology. 2009; 150, 4999-5009.

22. Carlin J, George R, Reyes TM. Methyl donor supplementation blocks the adverse effects of maternal high fat diet on offspring physiology. PLoS One. 2013; 8, e63549.

23. Rodriguez JS, Rodriguez-Gonzalez GL, Reyes-Castro LA, et al. Maternal obesity in the rat programs male offspring exploratory, learning and motivation behavior: prevention by dietary intervention pre-gestation or in gestation. Int J Dev Neurosci. 2012; 30, 75-81.

24. Margulis SW. Relationships among parental inbreeding, parental behaviour and offspring viability in oldfield mice. Anim Behav. 1998; 55, 427-438.

25. Vrana PB, Shorter KR, Szalai G, et al. Peromyscus (deer mice) as developmental models. Wiley Interdiscip Rev Dev Biol. 2014; 3, 211-230.

26. Rosenfeld CS, Johnson SA, Ellersieck MR, Roberts RM. Interactions between parents and parents and pups in the monogamous California mouse (Peromyscus californicus). PloS One. 2013; 8, e75725.

27. Carmon JL, Williams RG, Golley FB. Effects of temperature and radiation on litter size and growth in Peromyscus polionotus. Growth. 1967; 31, 79-89.

28. Good TC, Harris KK, Ihunnah CA. Corticosteroids as potential mechanism regulating variability in reproductive success in monogamous oldfield mice (Peromyscus polionotus). Physiol Behav. 2005; 86, 96-102.
29. Hoffman JI, Simpson F, David P, et al. High-throughput sequencing reveals inbreeding depression in a natural population. Proc Natl Acad Sci U S A. 2014; 111, 3775-3780.

30. McCoy G, Finlay MF, Rhone A, James K, Cobb GP. Chronic polychlorinated biphenyls exposure on three generations of oldfield mice (Peromyscus polionotus): effects on reproduction, growth, and body residues. Arch Environ Contam Toxicol. 1995; 28, 431-435.

31. Mullen LM, Hoekstra HE. Natural selection along an environmental gradient: a classic cline in mouse pigmentation. Evolution. 2008; 62, 1555-1570.

32. Oriel RC, Wiley CD, Dewey MJ, Vrana PB. Adaptive genetic variation, stress and glucose regulation. Dis Model Mech. 2008; 1, 255-263.

33. Scarth RD, Leverett CO, Scarth LL, Smith MH, Carmon JL. Effects of temperature, radiation and sex on body composition in Peromyscus polionotus. Growth. 1973; 37, 311-321.

34. Shorter KR, Owen A, Anderson V, et al. Natural genetic variation underlying differences in Peromyscus repetitive and social/ aggressive behaviors. Behav Genet. 2014; 44, 126-135.

35. Steiner CC, Rompler H, Boettger LM, Schoneberg T, Hoekstra HE. The genetic basis of phenotypic convergence in beach mice: similar pigment patterns but different genes. Mol Biol Evol. 2009; 26, 35-45.

36. Steiner CC, Weber JN, Hoekstra HE. Adaptive variation in beach mice produced by two interacting pigmentation genes. PLoS Biol. 2007; 5, e219.

37. Trainor BC, Finy MS, Nelson RJ. Rapid effects of estradiol on male aggression depend on photoperiod in reproductively non-responsive mice. Horm Behav. 2008; 53, 192-199.

38. Trainor BC, Martin LB 2nd, Greiwe KM, Kuhlman JR, Nelson RJ. Social and photoperiod effects on reproduction in five species of Peromyscus. Gen Comp Endocrinol. 2006; 148, 252-259.

39. Trainor BC, Rowland MR, Nelson RJ. Photoperiod affects estrogen receptor alpha, estrogen receptor beta and aggressive behavior. Eur J Neurosci. 2007; 26, 207-218.

40. Weber JN, Peterson BK, Hoekstra HE. Discrete genetic modules are responsible for complex burrow evolution in Peromyscus mice. Nature. 2013; 493, 402-405.

41. Wolfe JL, Esher RJ. Toxicity of carbofuran lindane to the oldfield mouse (Peromyscus polionotus) and the cotton mouse (P. gossypinus). Bull Environ Contam Toxicol. 1980; 24, 894-902.

42. Wolfe JL, Esher RJ, Robinson KM, Yarbrough JD. Lethal and reproductive effects of dietary mirex and DDT on old-field mice, Peromyscus polionotus. Bull Environ Contam Toxicol. 1979; 21, 397-402.

43. O'Neill RJ, Vrana PB, Rosenfeld CS. Maternal methyl supplemented diets and effects on offspring health. Front Genet. 2014; 5, 289.

44. Lewis MH, Tanimura Y, Lee LW, Bodfish JW. Animal models of restricted repetitive behavior in autism. Behav Brain Res. 2007; 176, 66-74.

45. Muehlmann AM, Bliznyuk N, Duerr I, Lewis MH. Repetitive motor behavior: further characterization of development and temporal dynamics. Dev Psychobiol. 2015; 57, 201-211.

46. Tanimura Y, King MA, Williams DK, Lewis MH. Development of repetitive behavior in a mouse model: roles of indirect and striosomal basal ganglia pathways. Int J Dev Neurosci. 2011; 29, 461-467. 
47. Englund-Ogge L, Brantsaeter AL, Sengpiel V, et al. Maternal dietary patterns and preterm delivery: results from large prospective cohort study. BMJ. 2014; 348, g1446.

48. Binder NK, Hannan NJ, Gardner DK. Paternal diet-induced obesity retards early mouse embryo development, mitochondrial activity and pregnancy health. PLoS One. 2012; 7, e52304.

49. Binder NK, Mitchell M, Gardner DK. Parental diet-induced obesity leads to retarded early mouse embryo development and altered carbohydrate utilisation by the blastocyst. Reprod Fertil Dev. 2012; 24, 804-812.

50. Mitchell M, Bakos HW, Lane M. Paternal diet-induced obesity impairs embryo development and implantation in the mouse. Fertil Steril. 2011; 95, 1349-1353.

51. Ng SF, Lin RC, Laybutt DR, et al. Chronic high-fat diet in fathers programs beta-cell dysfunction in female rat offspring. Nature. 2010; 467, 963-966.

52. Ng SF, Lin RC, Maloney CA, et al. Paternal high-fat diet consumption induces common changes in the transcriptomes of retroperitoneal adipose and pancreatic islet tissues in female rat offspring. FASEB J. 2014; 28, 1830-1841.

53. Binder NK, Beard SA, Kaitu'u-Lino TJ, et al. Paternal obesity in a rodent model affects placental gene expression in a sexspecific manner. Reproduction. 2015; 149, 435-444.

54. Kirkland G, Layne J eds. Advances in the Study of Peromyscus (Rodentia). 1989. Texas Tech University Press: Lubbock, TX.

55. Rosenfeld CS, Grimm KM, Livingston KA, et al. Striking variation in the sex ratio of pups born to mice according to whether maternal diet is high in fat or carbohydrate. Proc Natl Acad Sci US A. 2003; 100, 4628-4632.

56. Wu T, Deng S, Li WG, et al. Maternal obesity caused by overnutrition exposure leads to reversal learning deficits and striatal disturbance in rats. PLoS One. 2013; 8, e78876.

57. Jasarevic E, Williams SA, Roberts RM, Geary DC, Rosenfeld CS. Spatial navigation strategies in Peromyscus: a comparative study. Anim Behav. 2012; 84, 1141-1149.

58. Jasarevic E, Williams SA, Vandas GM, et al. Sex and dosedependent effects of developmental exposure to bisphenol A on anxiety and spatial learning in deer mice (Peromyscus maniculatus bairdii) offspring. Horm Behav. 2013; 63, 180-189.

59. Jasarevic E, Sieli PT, Twellman EE, et al. Disruption of adult expression of sexually selected traits by developmental exposure to bisphenol A. Proc Natl Acad Sci US A. 2011; 108, 11715-11720.

60. Williams SA, Jasarevic E, Vandas GM, et al. Effects of developmental bisphenol A exposure on reproductive-related behaviors in California mice (Peromyscus californicus): a monogamous animal model. PLoS One. 2013; 8, e55698.

61. Rosenfeld CS, Ferguson SA. Barnes maze testing strategies with small and large rodent models. J Vis Exp. 2014; 84, e51194.

62. Fountain ED, Mao J, Whyte JJ, et al. Effects of diets enriched in omega-3 and omega- 6 polyunsaturated fatty acids on offspring sexratio and maternal behavior in mice. Biol Reprod. 2008; 78, 211-217.

63. Johnson SA, Painter MS, Javurek AB, et al. Sex-dependent effects of developmental exposure to bisphenol A and ethinyl estradiol on metabolic parameters and voluntary physical activity. J Dev Orig Health Dis. 2015; 6, 539-552.

64. Steel RG. Principles and Procedures of Statistics: A Biometrical Approach, 3rd edn, 1996. McGraw-Hill Higher Education: New York.

65. Page KC, Jones EK, Anday EK. Maternal and postweaning highfat diets disturb hippocampal gene expression, learning, and memory function. Am J Physiol Regul Integr Comp Physiol. 2014; 306, R527-R537.

66. Tozuka Y, Kumon M, Wada E, et al. Maternal obesity impairs hippocampal BDNF production and spatial learning performance in young mouse offspring. Neurochem Int. 2010; 57, 235-247.

67. Agnoux AM, Antignac JP, Simard G, et al. Time window-dependent effect of perinatal maternal protein restriction on insulin sensitivity and energy substrate oxidation in adult male offspring. Am J Physiol Regul Integr Comp Physiol. 2014; 307, R184-R197.

68. Ellis-Hutchings RG, Zucker RM, Grey BE, et al. Altered health outcomes in adult offspring of Sprague Dawley and Wistar rats undernourished during early or late pregnancy. Birth Defects Res $B$ Dev Reprod Toxicol. 2010; 89, 396-407.

69. Rabadan-Diehl C, Nathanielsz P. From mice to men: research models of developmental programming. J Dev Orig Health Dis. 2013; 4, 3-9.

70. Yang KF, Shen XH, Cai W. Prenatal and early postnatal exposure to high-saturated-fat diet represses Wnt signaling and myogenic genes in offspring rats. Exp Biol Med (Maywood). 2012; 237, 912-918.

71. Johnson SA, Javurek AB, Painter MS, et al. Effects of developmental exposure to bisphenol A on spatial navigational learning and memory in rats: a CLARITY-BPA study. Horm Behav. 2015; 80, 139-148.

72. Sasaki A, de Vega WC, St-Cyr S, Pan P, McGowan PO. Perinatal high fat diet alters glucocorticoid signaling and anxiety behavior in adulthood. Neuroscience. 2013; 240, 1-12.

73. Bilbo SD, Tsang V. Enduring consequences of maternal obesity for brain inflammation and behavior of offspring. FASEB J. 2010; 24, 2104-2115.

74. Peleg-Raibstein D, Luca E, Wolfrum C. Maternal high-fat diet in mice programs emotional behavior in adulthood. Behav Brain Res. 2012; 233, 398-404.

75. Weiss R, Dziura J, Burgert TS, et al. Obesity and the metabolic syndrome in children and adolescents. N Engl J Med. 2004; 350, 2362-2374.

76. Whitaker RC. Predicting preschooler obesity at birth: the role of maternal obesity in early pregnancy. Pediatrics. 2004; 114, e29-e36.

77. Boney CM, Verma A, Tucker R, Vohr BR. Metabolic syndrome in childhood: association with birth weight, maternal obesity, and gestational diabetes mellitus. Pediatrics. 2005; 115, e290-e296.

78. Desai RA, Manley M, Desai MM, Potenza MN. Gender differences in the association between body mass index and psychopathology. CNS Spectr. 2009; 14, 372-383.

79. Rofey DL, Kolko RP, Iosif AM, et al. A longitudinal study of childhood depression and anxiety in relation to weight gain. Child Psychiatry Hum Dev. 2009; 40, 517-526.

80. Dewsbury DA. Wheel-running behavior in 12 species of muroid rodents. Behav Processes. 1980; 5, 271-280.

81. Cunha Fda S, Dalle Molle R, Portella AK, et al. Both food restriction and high-fat diet during gestation induce low birth weight and altered physical activity in adult rat offspring: the "Similarities in the Inequalities” model. PLoS One. 2015; 10, e0118586.

82. Liu Y, Peterson KE. Maternal exposure to synthetic chemicals and obesity in the offspring: recent findings. Curr Environ Health Rep. 2015; 2, 339-347.

83. Schneider JE, Brozek JM, Keen-Rhinehart E. Our stolen figures: the interface of sexual differentiation, endocrine disruptors, maternal programming, and energy balance. Horm Behav. 2014; 66, 104-119. 
84. Schug TT, Janesick A, Blumberg B, Heindel JJ. Endocrine disrupting chemicals and disease susceptibility. J Steroid Biochem Mol Biol. 2011; 127, 204-215.

85. Donovan EL, Hernandez CE, Matthews LR, et al. Periconceptional undernutrition in sheep leads to decreased locomotor activity in a natural environment. J Dev Orig Health Dis. 2013; 4, 296-299.

86. Vickers MH, Breier BH, McCarthy D, Gluckman PD. Sedentary behavior during postnatal life is determined by the prenatal environment and exacerbated by postnatal hypercaloric nutrition. Am J Physiol Regul Integr Comp Physiol. 2003; 285, R271-R273.

87. Baker MS, Li G, Kohorst JJ, Waterland RA. Fetal growth restriction promotes physical inactivity and obesity in female mice. Int J Obes (Lond). 2013; 39, 98-104.

88. Swaminathan S, Thomas T, Yusuf S, Vaz M. Clustering of diet, physical activity and overweight in parents and offspring in South India. Eur J Clin Nutr. 2013; 67, 128-134.

89. Rhodes JS, Garland T Jr., Gammie SC. Patterns of brain activity associated with variation in voluntary wheel-running behavior. Behav Neurosci. 2003; 117, 1243-1256.

90. Waters RP, Pringle RB, Forster GL, et al. Selection for increased voluntary wheel-running affects behavior and brain monoamines in mice. Brain Res. 2013; 1508, 9-22.

91. Roberts MD, Brown JD, Company JM, et al. Phenotypic and molecular differences between rats selectively bred to voluntarily run high vs. low nightly distances. Am J Physiol Regul Integr Comp Physiol. 2013; 304, R1024-R1035.

92. Hill LE, Droste SK, Nutt DJ, Linthorst AC, Reul JM. Voluntary exercise alters GABA(A) receptor subunit and glutamic acid decarboxylase- 67 gene expression in the rat forebrain. J Psychopharmacol. 2010; 24, 745-756.

93. Meeusen R. Exercise and the brain: insight in new therapeutic modalities. Ann Transplant. 2005; 10, 49-51.

94. Tarr BA, Kellaway LA, St Clair Gibson A, Russell VA. Voluntary running distance is negatively correlated with striatal dopamine release in untrained rats. Behav Brain Res. 2004; 154, 493-499.

95. Kolb EM, Rezende EL, Holness L, et al. Mice selectively bred for high voluntary wheel running have larger midbrains: support for the mosaic model of brain evolution. J Exp Biol. 2013; 216(Pt 3), 515-523.

96. Teske JA, Perez-Leighton CE, Billington CJ, Kotz CM. Role of the locus coeruleus in enhanced orexin A-induced spontaneous physical activity in obesity-resistant rats. Am J Physiol Regul Integr Comp Physiol. 2013; 305, R1337-R1345.

97. Werme M, Messer C, Olson L, et al. Delta FosB regulates wheel running. J Neurosci. 2002; 22, 8133-8138.

98. Alyea RA, Watson CS. Differential regulation of dopamine transporter function and location by low concentrations of environmental estrogens and 17beta-estradiol. Environ Health Perspect. 2009; 117, 778-783.

99. Jones DC, Miller GW. The effects of environmental neurotoxicants on the dopaminergic system: a possible role in drug addiction. Biochem Pharmacol. 2008; 76, 569-581.

100. Matsuda S, Saika S, Amano K, Shimizu E, Sajiki J. Changes in brain monoamine levels in neonatal rats exposed to bisphenol A at low doses. Chemosphere. 2010; 78, 894-906.

101. Nakamura K, Itoh K, Yoshimoto K, Sugimoto T, Fushiki S. Prenatal and lactational exposure to low-doses of bisphenol A alters brain monoamine concentration in adult mice. Neurosci Lett. 2010; 484, 66-70.
102. Tanida T, Warita K, Ishihara K, et al. Fetal and neonatal exposure to three typical environmental chemicals with different mechanisms of action: mixed exposure to phenol, phthalate, and dioxin cancels the effects of sole exposure on mouse midbrain dopaminergic nuclei. Toxicol Lett. 2009; 189, 40-47.

103. Zhou R, Zhang Z, Zhu Y, Chen L, Sokabe M. Deficits in development of synaptic plasticity in rat dorsal striatum following prenatal and neonatal exposure to low-dose bisphenol A. Neuroscience. 2009; 159, 161-171.

104. Garland T Jr, Schutz H, Chappell MA, et al. The biological control of voluntary exercise, spontaneous physical activity and daily energy expenditure in relation to obesity: human and rodent perspectives. J Exp Biol. 2011; 214(Pt 2), 206-229.

105. Chen ZY, Jing D, Bath KG, et al. Genetic variant BDNF (Val66Met) polymorphism alters anxiety-related behavior. Science. 2006; 314, 140-143.

106. Berchtold NC, Kesslak JP, Pike CJ, Adlard PA, Cotman CW. Estrogen and exercise interact to regulate brain-derived neurotrophic factor mRNA and protein expression in the hippocampus. Eur J Neurosci. 2001; 14, 1992-2002.

107. Teske JA, Billington CJ, Kotz CM. Mechanisms underlying obesity resistance associated with high spontaneous physical activity. Neuroscience. 2014; 256, 91-100.

108. Kotz C, Nixon J, Butterick T, et al. Brain orexin promotes obesity resistance. Ann N Y Acad Sci. 2012; 1264, 72-86.

109. Perez-Leighton CE, Billington CJ, Kotz CM. Orexin modulation of adipose tissue. Biochim Biophys Acta. 2014; 1842, 440-445.

110. Perez-Leighton CE, Boland K, Billington CJ, Kotz CM. High and low activity rats: elevated intrinsic physical activity drives resistance to diet-induced obesity in non-bred rats. Obesity (Silver Spring). 2013; 21, 353-360.

111. Perez-Leighton CE, Boland K, Teske JA, Billington C, Kotz $\mathrm{CM}$. Behavioral responses to orexin, orexin receptor gene expression, and spontaneous physical activity contribute to individual sensitivity to obesity. Am J Physiol Endocrinol Metab. 2012; 303, E865-E874.

112. Gaillard R. Maternal obesity during pregnancy and cardiovascular development and disease in the offspring. Eur J Epidemiol. 2015; 30, 1141-1152.

113. Horan MK, McGowan CA, Gibney ER, et al. Maternal nutrition and glycaemic index during pregnancy impacts on offspring adiposity at 6 months of age-analysis from the ROLO randomised controlled trial. Nutrients. 2016; 8, pii: E7. DOI:10.3390/nu8010007.

114. Houghton LC, Ester WA, Lumey LH, et al. Maternal weight gain in excess of pregnancy guidelines is related to daughters being overweight 40 years later. Am J Obstet Gynecol. 2016; 215, e241-248.

115. Kojima S, Catavero C, Rinaman L. Maternal high-fat diet increases independent feeding in pre-weanling rat pups. Physiol Behav. 2016; 157, 237-245.

116. Zambrano E, Ibanez C, Martinez-Samayoa PM, et al. Maternal obesity: lifelong metabolic outcomes for offspring from poor developmental trajectories during the perinatal period. Arch Med Res. 2016; 47, 1-12.

117. Johnson SA, Javurek AB, Painter MS, et al. Disruption of parenting behaviors in California mice, a monogamous rodent species, by endocrine disrupting chemicals. PLoS One. 2015; 10, e0126284. 